\title{
Da Dialética às Novas Tecnologias: Mudando os Contextos de Transmissão da História da Humanidade
}

\author{
João Cleber Ferreira Limal ${ }^{1}$, Rita Edevanira de Sá Carneiro ${ }^{2}$; Gislaine Farias de Oliveira ${ }^{3}$
}

\begin{abstract}
Resumo: O surgimento de novas tecnologias tem impulsionado novas formas de relações sociais e de trabalho. Estas mudanças acontecem em tempos diferentes e em momentos sociais diferentes, impactando em mudanças na própria forma de ensinar a História. O presente estudo pretende discutir aspectos relacionados ao ensino da história, bem como a sua função social. Os resultados nos levam a crer que o ensino da história mudou, acompanhando os contextos das novas tecnologias de transmissão dos conteúdos. Atualmente professores tem se prestado a trabalhar com conteúdos históricos abertos e variados, que possam ser refletidos e adaptados a novos contextos. Não com conteúdos fechados, viciados e determinados, como ainda acontece comumente em alguns lugares. A finalidade última do ensino da história, certamente é nos levar a um desfecho positivo em relação à vida democrática e social.
\end{abstract}

Palavras Chaves: Ensino da História, Tecnologias educacionais, Educação

\section{Dialectic of the New Technologies: Changing Contexts Transmission of human history}

\begin{abstract}
The emergence of new technologies has driven new forms of social relationships and work . These changes happen at different times and in different social times, impacting on changes in own way to teach history. This study aims to discuss aspects related to the teaching of history as well as its social function. The results lead us to believe that the teaching of History has changed, following the contexts of new transmission technologies of the content. Currently teachers has been given to working with historical contents opened and varied, and adapted to be reflected in new contexts . Not content with closed addicts and determined, as is still common in some places. The ultimate purpose of teaching History, it is certainly lead us to a positive outcome in relation to social and democratic life.
\end{abstract}

Key Words : History Teaching, Educational Technology, Education

\section{Introdução}

O ensino da História sempre, ao longo do tempo, tende a nos reportar a muitas dimensões em termos dos sentidos que suscita. Esta situação estaria associada às próprias mudanças porque passam os tempos atuais. As situações e maneiras de percebê-las tem mudado.

\footnotetext{
${ }^{1}$ Graduado em História pela Universidade Federal da Paraíba - UFPB e em Pedagogia pela Universidade Estadual do Vale do Acaraú UVA. Especialista em Docência do Ensino Superior e em Metodologia do Ensino. Mestrando em Ciências da Educação pela Universidad San Carlos - PY. E-mail: jcleberflima2@gmail.com

${ }^{2}$ Rita Edevanira de Sá Carneiro é graduada em Ciências Biológicas pela Universidade Regional do Cariri - URCA. Especialista em Gestão Escolar e em Mídias na Educação pela Universidade Federal do Ceará - UFC. E-mail: edevanira@ yahoo.com.br.

${ }^{3}$ Bacharel em Administração de Empresas e Pós-Graduada em Geografia com ênfase nas questões ambientais.

E-mail: gisleinefarias44@hotmail.com;
} 
http://idonline.emnuvens.com.br/id ISSN on-line: 1981-1179

Também por conta de uma série de transformações paradigmáticas, crise nos valores sociais, que, consequentemente vão dando contornos e conotações diferentes a história do nosso mundo.

O surgimento de novas tecnologias tem impulsionado novas formas de relações sociais e de trabalho. Estas mudanças acontecem em tempos diferentes e em momentos sociais diferentes, impactando em mudanças na própria forma de ensinar a História.

Os limites das nações, a ideia que se faz de progresso, espaço, sexo e sexualidade, casamento, trabalho e local de trabalho, são apenas alguns ingredientes que marcam uma época e que, portanto, precisam ser compreendidos, interpretados em cada contexto e repassados, juntamente com seus significados, enquanto história da humanidade, às próximas gerações.

A história da humanidade tende a reforçar laços culturais e familiares. Porém as discussões propostas pelo ensino da história, tende a tornar os acontecimentos históricos, algo dinâmico, que levam a posturas interpretativas que nem sempre dão conta da realidade, porém proporcionam questionamentos salutares sobre a forma de proceder das sociedades.

É possível que, em alguma época num passado, não muito distante, o ensino da história nas escolas, se limitava a estudos sobre moral e civismo, sem um aprofundamento das questões sociais e culturais envolvidas. Essa postura tinha o objetivo de manter e legitimar uma ordem social e política, ao mesmo inculcar nos membros da nação, uma espécie de orgulho de pertencerem a esta nação e, portanto, devendo a esta respeito e dedicação em servi-la. A máquina educacional pública, também reforçaria esta forma de proceder, através de estratégias simples: narrativas de fatos selecionados de maneira apropriada ao objetivo acima comentado, escolha de momentos fortes, grandes personagens, acontecimentos simbólicos.

Essa forma de ensinar a história foi se tornando desnecessária, na medida em que as nações foram sentindo-se fortalecidas na manutenção de sua própria existência. Observe-se que, nos países ocidentais, o marco foi o fim da Segunda Guerra Mundial, cujo resultado foi percebido como uma vitória da democracia.

Nessa democracia a que faz-se referência, em princípio, não se discutia mais a partir de então, mas que precisava agora funcionar de uma maneira mais correta, ou seja, com a participação dos cidadãos, de acordo com o princípio democrático. A idéia de cidadão que participa começou a substituir a de cidadão apenas cumpridor das leis . O ensino da história ganha com isso. A função da educação para a cidadania democrática substituiu sua função anterior de mantenedora da instrução nacional.

Portanto, a partir de agora, é preciso tornar nossos jovens capazes de participar democraticamente da sociedade, além de se procurar desenvolver neles capacidades intelectuais e recursos afetivos necessárias para tal. Dessa forma, os conteúdos passam a ser menos determinados a

Id en line Revista de Psicologia. Ano 7, No. 21, Novembroo/2013 - ISSN 1981-1179. Edição eletrônica em http://idonline.emnuvens.com.br/id 
http://idonline.emnuvens.com.br/id

ISSN on-line: 1981-1179

priori, menos exclusivos, aberto a diversidade e ao relativo. O mais importante é o entendimento que, o desenvolvimento das capacidades se dá com uma prática, associada a uma pedagogia centrada nas aprendizagens dos alunos.

Nos países ocidentais, esse caminho parece ter sido percorrido mais cedo. É o que ocorre em muitos outros países espalhados pelos outros continentes. É relativamente fácil de se constatar. É só examinar os programas propostos e o discurso associado, com o qual é apresentado atualmente o ensino da história. Entretanto, em muitos desses países, quando há críticas ao ensino da história, como muitas vezes acontece, isso não se dá porque as pessoas se inquietam ao alcançar os objetivos de formação, mas em razão dos conteúdos dos fatos, por se julgar que certos elementos estariam ausentes em detrimento de outros menos necessários que estariam sendo ensinados. Como se o ensino da história fosse um veículo de narração apenas, que precisa ser assimilada de qualquer maneira. Vê-se aí um paradoxo de um ensino destinado a cumprir uma função pré-determinada, mas acusado de não cumprir uma outra que, não lhe deveria ser mais atribuída.

Há muitos casos assim neste fim de século. Em conclusão consideraremos um outro paradoxo que decorre desse primeiro: o de se acreditar que, através da manipulação dos conteúdos, é possível direcionar as consciências ou as memórias. Experiências têm demonstrado que isso está longe de acontecer. Assim, não passa de uma ilusão.

\section{Situações reais que exemplificam a manutenção de uma ordem estabelecida}

Em geral, o que se evidencia estar em jogo, é o respeito aos conteúdos do ensino da história, na manutenção de uma determinada tradição. Observe-se o caso do National Standards for History nos Estados Unidos, onde a educação é de responsabilidade dos Estados. Não da administração federal.

Há algum tempo, o governo federal americano, mostrava-se inquieto com relação ao ensino da história, por algumas razões. Em primeiro lugar, porque se julgava que homens de negócios, perdiam muito por não conhecerem suficientemente as culturas estrangeiras; e também, porque se acreditava que a história facilitaria uma integração das minorias culturais. A administração Reagan, em um relatório sobre a educação, fez referência à educação histórica; Bill Clinton, através dos governadores dos Estados, fez aprovar um projeto de reforma da educação, conhecido por America $2000^{1}$, que insistia que o ensino da história se tornasse matéria básica em todos os níveis educacionais. Outros projetos também se preocupavam com a derrocada dos conhecimentos culturais dos jovens americanos, abrindo espaço para o ensino de ciências sociais, ao lado de disciplinas tradicionais como a história e a geografia (HIRSCH, 1988; RAVITCH e FINN, 1987; CHENEY, 1987). 
http://idonline.emnuvens.com.br/id

ISSN on-line: 1981-1179

Nesse contexto, um grupo de historiadores e pedagogos, em conjunto com outra centena de consultores externos e especialistas oriundos de muitos lugares, elaboraram um projeto de normas nacionais para subsidiar o ensino da história (NATIONAL STANDARDS FOR HISTORY FOR GRADE K-4, 1994). Este documento, deveria servir como base para as reflexões, a título de sugestão, porém tomou rumos políticos, o que transformou-se em questão de ordem nacional, enfurecendo os partidos de direita.

Nesta direção, as normas contidas no documento oficial, pareciam estar insuflando um relativismo cultural, que colocava em perigo a civilização ocidental branca e cristã e, por conseguinte, a civilização americana. Ao promover uma abertura à história social, às mulheres e aos imigrantes, aos negros, bem como ao tratar questões de racismo como a Klu Klux Klan e do McCartysmo, essas normas estariam querendo obscurecer heróis nacionais como Washington, Thomas Edison ou Paul Revere, deixando pouco espaço para a Constituição federal (NASH, CRABTREE e DUNN, 1997; WINKLER, 1995). Mesmo que o governo ao nível federal, nada ou pouco interferisse na educação, New Gingrich, que era o líder republicano na Câmara, na época, conseguiu levar a questão ao Senado e influenciou os senadores a se pronunciarem sobre os documentos. 99 deles votaram contra, apenas um.

$\mathrm{Na}$ Inglaterra houvera, algum tempo antes, um debate semelhante, relativamente ao ensino da história. Lá não havia um programa nacional específico para essa disciplina. Neste caso, as escolas e os professores tinham alguma liberdade na definição e na prática do ensino. Havia contudo, um programa chamado Schools Council History Project, que, de alguma forma, determinava alguma influência sobre o ensino de história, de uma maneira geral. Tratava-se de um moderno programa que seguia uma tendência dos programas atuais, mas que era ensinado com grande liberdade, pelos professores britânicos, portanto, havia uma variedade visível nos conteúdos.

Margaret Thatcher, à frente do país à época, preocupava-se com isso. Era preciso ensinar sobre a Inglaterra e seu passado glorioso, porém, de maneira a tornar a história facilmente acessível aos alunos. Com assuntos próximos da realidade deles, evitando-se a aquisição de uma memória comum, somente britânica.

Iniciou-se então, a preparação de exames nacionais, seguidos de um programa nacional de história, conhecido como o National Curriculum for History ${ }^{l}$, com os conteúdos influenciados pelos conservadores, é claro. Mais uma vez, o debate em torno dos conteúdos, na mídia, na opinião pública, entre os consultores, foi intenso, durando vários anos ${ }^{2}$.

\footnotetext{
${ }^{1}$ Department of Education. History in the National Curriculum, Londres, HMSO.

${ }^{2} \mathrm{Em}$ "La bataille des programmes. Le débat sur l'enseignement de l'histoire et la recherche en Allemagne de l'Ouest, en Grande-Bretagne et en Suède". In Revue d'Allemagne, vol. 25, n 02, 1993, pp. 203-211.
} 
No final, os professores, acabaram conseguindo um acordo. Este passou a vigorar desde o início do ano de 1995, e preservava em parte, os objetivos de formação, cujos professores queriam conservar, embora com muitos conteúdos pré-determinados.

Outro debate não menos acalorado agitou a França no final da década de 1970 e início da década de 1980, na implantação da reforma dos programas de história. Pela primeira vez, era quebrada uma tradição nos programas que havia se iniciado na Terceira República.

Conteúdos centrados no aluno e orientados para desenvolver capacidades cognitivas básicas, privilegiava uma pedagogia de aprendizagem pela descoberta, não uma pedagogia receptiva. O novos programas pareciam negligenciar alguns dos grandes personagens nacionais. Houve uma certa indignação em todas as famílias política. Dois presidentes, em mandatos sucessivos, vieram juntar-se aos indignados. Foram eles, Valéry Giscard-d'Estaing e, em seguida, François Mitterrand. Este último declarou estar escandalizado e angustiado com o ensino da história ${ }^{3}$. Em meados da década de 1980, a França volta ao que havia de mais convencional.

Em resumo, nota-se o quão interessante, quanta vigilância e quantas foram as intervenções no ensino da história no mundo. A história é certamente, uma disciplina escolar com intervenções diretas dos mais altos dirigentes da nação. Isso demonstra sua importância para o poder constituído.

\section{Outros exemplos de intervenções estatais no ensino da história, no mundo}

Outras situações são também ilustrativas de fortes intervenções governamentais na área educacional, mais especificamente no ensino da história. No final da II Grande Guerra mundial, o alto comando aliado em Berlim proibiu o ensino da história nos países vencidos, com o objetivo de neutralizar seus conteúdos anteriores e substituí-los por outros. Essa mesma situação acometeu a Itália e o Japão. Mesmo em dias atuais, ainda acontecem situações semelhantes quando da passagem de um regime para outro, como aconteceu bem recentemente nos ex-países do leste europeu.

Naqueles países, mal se iniciou a transição, e o ensino de história já estava sendo submetido a uma revisão nos seus programas e manuais, mais do que a própria pedagogia aplicada, já que se trata principalmente da questão de narrativa. Tal revisão consiste em se reescrever, ocultando aquilo que se quer apagar da memória, referentes ao antigo regime, introduzindo ou reintroduzindo novas memórias, de acordo com o que consideram conveniente, como aconteceu na ex-Alemanha Oriental (AHONEN, 1992).

\footnotetext{
${ }^{3}$ Entre outras obras sobre a polêmica, leia-se Des enfants sans histoire. Enquête de Jean-François Fayard. Paris, Perrin, 1984.
} 
http://idonline.emnuvens.com.br/id ISSN on-line: 1981-1179

Segundo Sirkka Ahonem (1992), naquele país, de uma hora para outra, foram subtraídos os manuais de história e seus professores suspensos. Isso provocou reações. Os sindicatos passaram a intervir nos meios de comunicação, inclusive os estrangeiros, de forma que todos abordavam o assunto. Decidiu-se pois, que os professores deveriam ser recontratados, porém após passarem por um exame, que seria baseado no pensamento liberal. Outros exames do mesmo tipo seriam também empregados noutros lugares, incluindo nestes até questões sobre a Bíblia.

$\mathrm{Na}$ Alemanha, como manuais levariam algum tempo para serem refeitos, manuais foram importados da Alemanha Ocidental. Dessa forma, na Saxônia, um dos países mais avançados cultural e economicamente, o ano letivo de 1991 se iniciou com manuais de história da Baviera, lugar onde a corrente conservadora é muito importante.

Na República Tcheca, após os acontecimentos de 1989, foram postos no mercado, manuais de história bem antigos do Estado tcheco e tchecoslovaco, que foram publicados entre 1918 e 1938 ou entre 1945 e 1948 (CORNEJ, 1997). Em outros lugares, aconteceu de simplesmente serem feitas traduções de manuais de história estrangeiros, como na Rússia, onde houve a tradução explícita de um manual americano de história geral que, os jovens russos certamente acharam bem estranho (CORNEJ, 1997).

Observe-se que, os ex-países do leste europeu ofereceram interessantes exemplos da maneira como o ensino da história é tratada, quando um Estado é reconstituído. Imaginemos que, isso não aconteça somente nesses países, evidentemente, ocorrem tais situações em outros lugares do planeta.

Na África do Sul, por exemplo, houve um longo debate até se chegar a uma narrativa da história. Seria uma história negra? ou branca? e ainda, com que densidade relativa de branco ou de negro?. O Ministério da Educação elaborou um projeto para a redação de novos manuais, conseguindo a aprovação dos mesmos apenas para o ano 2000.

Na China, alguns meses antes da reanexação de Hong Kong, já era anunciada a revisão dos manuais, pois, como alegavam, os conteúdos de certos livros escolares, utilizados nas escolas em Hong Kong não estaria conforme a História e à realidade. Portanto não estariam compatíveis com as mudanças que iriam ocorrer em 1997.

Eram tidos como contrários ao espírito dos princípios do país (um país, dois sistemas, bem como à Constituição ${ }^{4}$.

No Japão, durante muitas décadas, professores e historiadores, apoiados por diversos grupos, combatem a censura imposta pelo Ministério da Educação, aos conteúdos dos manuais de história. Trata-se de uma censura muito rigorosa. Qualquer coisa que, a consideração do ministério, possa diminuir a imagem positiva do Japão na história, torna-se proibido (CONAN, 1995).

Id en line Revista de Psicologia. Ano 7, No. 21, Novembroo/2013 - ISSN 1981-1179.

Edição eletrônica em http://idonline.emnuvens.com.br/id 
http://idonline.emnuvens.com.br/id

ISSN on-line: 1981-1179

No México, mais precisamente em 1992, há uma coalizão de liberais e de progressistas que atacam, de forma brutal, os manuais de história para o primário, imposto pelo governo de Carlos Salinas. No contexto das negociações do mercado comum norte-americano, os manuais novos passaram a elogiar as políticas econômicas presentes e passadas do México e ainda, sua abertura ao capitalismo internacional, minimizando os episódios contestatórios e/ou revolucionários da história. Houve acalorados debates até que os manuais foram revistos (NASH, CRABTREE, DUNN, 1997).

No Brasil, um exemplo de como a narrativa histórica pode ser vista como uma tomada do poder por grupos que não têm poder, pode ser inferida de alguns Estados, principalmente em Minas Gerais e São Paulo. Nestes Estados, os professores de história lutaram durante a ditadura, para que se conseguisse um programa, cujo conteúdo pudesse ser definido de acordo com o ponto de vista dos militantes. Em Minas, desejavam se opor aos programas oficiais, que tinham um cunho nacionalista e positivista, Eram favoráveis a um conteúdo de história marxista clássico, onde realçasse as etapas sucessivas da formação econômica, bem como integrasse o nacional ao universal. Foi o caso de se trocar uma narrativa por outra narrativa. Esse programa somente foi conseguido, à partir da redemocratização mas agora, como o combate em grande parte, esgotou-se, parece que os professores fazem menos questão de afirmarem seu poder (SIMAN, 1997).

Em resumo, todos os exemplos ora apresentados, tratam sobre a fixação de narrativas histórica e/ou de sua manipulação, ocorridas no âmbito da nação.

Porém, pode-se considerar também, outras interferências tal como um Projeto que propunha oferecer uma narrativa aos alunos dos países muçulmanos, dentro de um programa islâmico de ensino da história.A ideia era a de ensinar, aos alunos dos diferentes países, que, mesmo tendo eles uma identidade nacional, eles pertenceriam antes de tudo, a uma grande comunidade dos muçulmanos (COMMISSION SCOLAIRE CRIE, 1994).

Seguem-se alguns trechos do projeto ISESCO (1998):

(...)"enraizar o aluno em sua identidade individual e nacional, fixando-o na comunidade muçulmana e destacando o fato de que sua identidade o liga intimamente, por meio de laços indeléveis, religiosos, históricos e culturais, à comunidade islâmica"; (...)"desenvolver no aluno o senso da responsabilidade e o sentimento de orgulho em relação à comunidade islâmica, com base na força desta e na convicção da necessidade de instaurar a unidade muçulmana em todos os setores"; (...) "o que procuramos destacar, através dos assuntos escolhidos para esse programa, é que os povos muçulmanos formaram, ao longo da história, uma única comunidade ligada por laços de cooperação e de complementaridade" (p.14-29).

\footnotetext{
4 “"Hong-Kong: 'un pays, deux systèmes', quelle histoire?". In Le Devoir. 11 de março de 1997.
} 
Trata-se de um programa que consiste numa extensa lista das matérias propostas para serem ensinadas, feitas sob medida para se alcançar uma única identidade.

Nestas ilustrações apresentadas vê-se um grande paradoxo: enquanto na maioria dos países, o objetivo do ensino da história está em desenvolver nos alunos as capacidades, que o habilitam a participar da sociedade de maneira mais autônoma e refletida, nestes casos apresentados, o ensino da história, é, muitas vezes, reduzido a uma narrativa fechada, que se destina principalmente a moldar as consciências e a manipular as obrigações e os comportamentos dos cidadãos para com a nação.

Tais observações, nos levam a constatação de um segundo paradoxo: o de se acreditar neste tipo de ensino da história. Pois não há como se regular as consciências e os comportamentos apenas por meio do ensino da história.

Um exemplo interessante está na ex-União Soviética, onde por várias décadas, se ensinava ali, por meio da história, que era o capitalismo o próprio inferno e, que o socialismo seria a salvação, isto é, abriria as portas ao paraíso. O que fizeram os membros das diversas repúblicas, no momento em que tiveram oportunidade? Escolheram o inferno. Outro exemplo, na Alemanha. Uma pesquisa mostrou que os jovens da Alemanha Ocidental e, da Alemanha Oriental, provenientes de sociedades que conheceram ensinos de história praticamente antagônicos, não apresentaram, no entanto, diferenças significativas em suas representações, conceitos e atitudes (LAVILLE, 1999).

É razoável concluir que, todos esses esforços em se tentar controlar os conteúdos do ensino da história, além dos próprios debates que essas situações provocam, nos impulsiona a pensar estarem alicerçados em uma ilusão, pois uma narrativa histórica não parece ter mais poder, que a cultura e os valores de uma família. Este sim, é o meio ao qual se pertence e se vive as circunstâncias marcantes no ambiente.

Portanto, o ensino da história tem sim uma função social, a qual não se pode nem deve perder de vista: formar indivíduos autônomos e críticos, bem como levá-los ao desenvolvimento de suas capacidades intelectuais e afetivas adequadas, de maneira que possam trabalhar com conteúdos históricos abertos e variados, que possam ser refletidos. Não com conteúdos fechados, viciados e determinados, como ainda acontece comumente em alguns lugares. A finalidade última do ensino da história, certamente é nos levar a um desfecho positivo em relação à vida democrática e social.

O grande desafio brasileiro hoje quanto ao ensino da História em geral, é que, em vez de se pautar em debates envolvendo questões filosóficas, sociológicas e da própria história, os educadores tratam da manutenção da disciplina em sala de aula. A escola parece que deixou de ser o lugar do enfrentamento na produção do conhecimento, isso é, impulsionando o professor a discutir, para ser um lugar de se fazer política partidária, com salas de aulas lotadas e sem infra-estrutura adequada (BARREIRO, 1998).

Id en line Revista de Psicologia. Ano 7, No. 21, Novembroo/2013 - ISSN 1981-1179.

Edição eletrônica em http://idonline.emnuvens.com.br/id 
http://idonline.emnuvens.com.br/id

ISSN on-line: 1981-1179

A nobre tarefa de ensinar acaba implicando em uma tarefa cansativa para professores e alunos e, a disciplina, algo monótono e sem atrativos, afastando a motivação para o debate. Portanto, não dependendo apenas de um maior número de leituras, pensar relações entre os estudos realizados, ou tampouco da capacidade individual dos educadores em assumir esta ou aquela posição teóricometodológica.

Então a focalização do problema começa a demandar um debate sobre a formação do educando e sobre o ato de ensinar a disciplina história. Mas ensinar o que? E, mais precisamente, a quem?. Moral e Cívica já tiveram sua época de glória no tempo da ditadura militar no nosso país. É preciso mais. É preciso estimular o homem a pensar, discutir sua cidadania, seu caráter e, mais que isso, formar cidadãos conscientes de seus direitos e deveres, objetivando uma sociedade mais humana, solidária.

\section{Referências}

AHONEN, Sirkka. Clio sans Uniform. A Study of the Post-Marxist Transformation of the History Curricula in East Germany and Estonia, 1986-1991. Helsinque, Suomalainen Tiedeakatemia, 1992.

BARREIRO, José Carlos. Os Parâmetros Curriculares Nacionais e os novos desafios da escola. In: História e cidadania XIX Simpósio Nacional de História ANPUH. 1998, p.584.

CHENEY, Lynn. American Memory: a Report on the Humanities in the Nation's Public Schools. Washington, NEH, 1987.

COMMISSION SCOLAIRE CRIE. Histoire du Québec et du Canada. Programme adapté, junho de 1994.

CONAN, Éric. "Le Japon ne veut pas d'histoire". In L'Express. 27 de julho de 1995, pp. 53-56.

CORNEJ, Petr. "Politique, histoire et histoire scolaire". In Revue internationale d'éducation. $\mathrm{n}^{\circ} 13$, março de 1997, p. 90. 
HIRSCH, E. D. Cultural Literacy. What every American needs to know. Nova Iorque, Vintage, 1988.

HORIO, Teruhisa. "Éducation et conscience politique". In Revue international d'éducation, op. cit., p.107;

ISESCO. Projet de programme d'enseignement de l'histoire islamique et de La géographie. s. 1., 1998, p.14, 29.

KLOSE, Dagmar. "Bouleversement de la conscience de l'histoire". In Revue internationale d'éducation. op. cit., p. 72.

LAVILLE, Christian. A guerra das narrativas: debates e ilusões em torno do ensino da história. Rev. Bras. De História. São Paulo, v.19. n.30. 1999. P. 125-138.

NASH, Gary B., CRABTREE, Charlotte e DUNN, Ross E. History on Trial: Culture Wars and the Teaching of the Past. New York, Alfred A. Knopf, 1997.

NATIONAL STANDARDS FOR HISTORY FOR GRADE K-4. Expanding Children's World in Time and Space; National Standards for United States History. Exploring the American Experience. Grade 5-12 et National Standards for World History. Exploring Paths to the Present. Grades 5-12. Los Angeles, National Center for History in the Schools, 1994.

RAVITCH, Diane et FINN, C. E. What do our 17-year-olds know? New York, Harper and Row, 1987;

SIMAN, Lana Mara de Castro. Changement paradigmatique et enjeux sociopolitiques en enseignement de l'histoire: le cas du programme d'histoire du Minas Gerais (Brésil) et les réactions paradoxales des enseignants. Tese de Doutorado, Université Laval, 1997.

WINKLER, Allan. "Who chopped down the cherry tree?". Times Higher Education Supplement, 10 de março de 1995, p.19.

Como citar este artigo (Formato ISO):

LIMA, J.C.F.; CARNEIRO, R.E.S.; OLIVEIRA, G.F. Da dialética às novas tecnologias: mudando os contextos de transmissão da história da humanidade. Id on Line Revista de Psicologia, Novembro de 2013, vol.1, n.21, p. 25-34. ISSN 1981-1189.

Id en line Revista de Psicologia. Ano 7, No. 21, Novembroo/2013 - ISSN 1981-1179.

Edição eletrônica em http://idonline.emnuvens.com.br/id 